\title{
Investigating the impact of demand side management on residential customers
}

DOI:

10.1109/ISGTEurope.2011.6162699

Link to publication record in Manchester Research Explorer

\section{Citation for published version (APA):}

Zhang, N., Ochoa, L. F., \& Kirschen, D. S. (2011). Investigating the impact of demand side management on residential customers. In IEEE PES Innovative Smart Grid Technologies Conference Europe/IEEE PES Innovative. Smart Grid Technol. Conf. Europe https://doi.org/10.1109/ISGTEurope.2011.6162699

\section{Published in:}

IEEE PES Innovative Smart Grid Technologies Conference Europe|IEEE PES Innovative. Smart Grid Technol. Conf. Europe

\section{Citing this paper}

Please note that where the full-text provided on Manchester Research Explorer is the Author Accepted Manuscript or Proof version this may differ from the final Published version. If citing, it is advised that you check and use the publisher's definitive version.

\section{General rights}

Copyright and moral rights for the publications made accessible in the Research Explorer are retained by the authors and/or other copyright owners and it is a condition of accessing publications that users recognise and abide by the legal requirements associated with these rights.

\section{Takedown policy}

If you believe that this document breaches copyright please refer to the University of Manchester's Takedown Procedures [http://man.ac.uk/04Y6Bo] or contact uml.scholarlycommunications@manchester.ac.uk providing relevant details, so we can investigate your claim.

\section{OPEN ACCESS}




\title{
Investigating the Impact of Demand Side Management on Residential Customers
}

\author{
Ning Zhang, Graduate Student Member, IEEE, Luis F. Ochoa, Member, IEEE, \\ Daniel S. Kirschen, Fellow, IEEE
}

\begin{abstract}
With the advent of smart meters and smart appliances, residential demand side management (DSM) schemes could potentially happen on a considerably larger scale. From the Distribution Network Operator perspective, intelligent control of appliances could help reduce peaks in demand and thus defer reinforcements of the low-voltage (LV) network. For the consumer, in a scenario where dynamic pricing is in place, peak reduction might also provide another strategy to reduce energy costs. However, the successful implementation of these techniques is contingent on the willingness of residential consumers to accept them. This, in turn, depends on the negative effects that this control might have on the consumers' comfort and convenience. This paper investigates the impact of a DSM scheme that shifts residential high-power appliances (loads) to reduce the overall peak of households connected to the same LV feeder. Simulations are run using high-resolution historical data for Central-East England. Results are encouraging; showing not only that the proposed DSM scheme has great potential for peak reduction, but, more importantly, that the negative impact on the consumers is minimal. These findings could be used to promote such schemes and increase public acceptance.
\end{abstract}

Index Terms-- Customer inconvenience, demand side management, energy efficiency, high-resolution domestic load data, residential electricity demand.

\section{INTRODUCTION}

$\mathrm{D}$ EMAND SIDE MANAGEMENT (DSM) is a mechanism through which the load of some customers is managed (i.e., reduced or shifted to a different time period) in response to certain conditions (e.g., price, network constraints, emergencies, etc.). As a concept, DSM is not new and has been applied by transmission and distribution network operators mainly to reduce costs or relieve dangerous system operating conditions. These activities usually involved mostly industrial and commercial customers and took place within an agreed contractual framework.

With the advent of smart meters and smart appliances, residential DSM schemes open up the possibility of applying such schemes on a much larger scale. Indeed, in the UK, residential customers account for approximately $36 \%$ of the

The research described in this paper was carried out as part of the Supergen Flexnet project sponsored by the UK's Engineering and Physical Sciences Research Council.

N. Zhang and L. F. Ochoa are with the School of Electrical \& Electronic Engineering, The University of Manchester; Manchester M13 9PL, U.K. (email: zhangn03@gmail.com, luis_ochoa@ieee.org). N. Zhang is also with the State Key Lab of Power Systems; Dept. of Electrical Engineering; Tsinghua University; Beijing, China, 100084.

D. S. Kirschen is with the University of Washington, Seattle, USA. (email:kirschen@uw.edu). total electricity demand [1], a figure that is roughly similar in most developed countries. Due to this potential, DSM at the residential level (i.e., low-voltage (LV) networks) has received increased attention over the last decade [1]-[4]. Indeed, a number of DSM approaches have been proposed in the literature [5]-[10]. Some of these are summarized below:

A) Load priority techniques: Domestic appliances of an individual consumer (or a group of consumers) are classified by their importance. When a given condition is reached, single loads (i.e., appliances) can be disconnected by a central management system according to the specified priority [5]-[6].

B) Control of appliances: Rather than disconnecting appliances, their power requirements are reduced or their operation is delayed [7]. It has been reported that peak load reductions of up to $60 \%$ could be achieved in UK households by developing 'load-conscious' control algorithms for cooking and washing appliances [1].

C) Differential tariffs: By using different electricity tariffs, for instance during peak and off-peak hours, residential consumers can be encouraged to adapt their behavior [5]-[8]. A practical example of this is the UK's Economy 7, where during 7 hours per day (at night) the load of the residential consumer is automatically switched to another energy meter where it is charged at a lower price. However, depending on how this is implemented in each household, the aggregation of off-peak load waiting to use the cheaper tariff can result in a "cold-load" pickup, and cause an even higher peak load [9].

D) Conservation voltage reduction: Given that the voltage influences the power required by some domestic loads, it is possible to lower the demand by adjusting the set point of LV transformers. In [10], it was estimated that a $1 \%$ drop in voltage results in a $1 \%$ reduction in load. Although this approach is limited by power quality considerations, its aggregated potential could be significant.

From the perspective of a Distribution Network Operator (DNO), reducing the demand during peak hours is probably the DSM application that brings the most immediate benefits. Indeed, in highly loaded LV circuits, it may be possible to defer network reinforcements (and hence significant investments) by decreasing the peak demand. The importance of peak load mitigation is likely to increase with the expansion in the number of electric vehicles [11] and the potential shift towards more electric heating.

In [8], it was shown that $25 \%$ to $45 \%$ of the UK domestic loads could potentially be made responsive to exogenous signals. While this and other studies show that DSM has an enormous potential of DSM schemes, one of the biggest 


\section{Accepted Paper}

barriers that these schemes are likely to face is the willingness of consumers to participate because they are perceived as reducing comfort or causing various inconveniences. A distinction is often made between schemes where consumers voluntarily change the pattern of their energy usage in response to price signals and schemes where part of their demand can be controlled by an external entity (such as their DNO. It is generally believed that, for a scheme that involves external control to be acceptable, it should not significantly affect the consumers' ability to use electricity. However, a question remains: To what extent will a given DSM scheme disturb/inconvenience residential customers? Given the nature of residential electricity consumption, with sudden changes due to the use of appliances, and low correlation between users, this question can only be answered by either trialing the scheme or simulating it with high-resolution data from a number of households.

In this work, one-minute resolution load data of 12 domestic consumers from the East Midlands region in England [12] are used. A DSM scheme for peak reduction at LV substations is proposed. In this scheme, high-power appliances (e.g., electric heating, showers) are inhibited from starting operation if a given power threshold has been reached. By comparing real-life historic data with the consumption resulting from the proposed DSM scheme it is possible to assess its impact on the household, i.e., how many times and for how long have high-power appliances been inhibited. Results are encouraging, showing not only that the proposed DSM scheme has great potential for peak reduction, but, more importantly, that the negative impact on the consumers is minimal. These findings could be used to promote such schemes and increase public acceptance.

The remainder of the paper is organized as follows: Section II describes the load data used for this work and how it was analyzed. Section III describes the proposed DSM scheme. Simulation results are presented and discussed in section IV. Finally, conclusions are drawn in section V.

\section{High-Resolution Residential LoAD DATA}

Data about the electricity consumption of $12 \mathrm{UK}$ households in the East Midlands region of England has been collected by Loughborough University from January 2008 to December 2009 [12]. This data has a sampling rate of one minute, and also includes a survey of the appliances used by each household. As is inevitable in studies involving field measurements, some data are missing. The proportion of missing data ranges from $5 \%$ to $75 \%$ depending on the household. Fig. 1 shows the two-year consumption pattern of a single household (recorded peak load: $8.53 \mathrm{~kW}$, load factor over whole the data available: 0.0518 ). The legend on the right side relates the colors to the load level measured in $\mathrm{kW}$. This color legend was re-scaled to emphasize the bottom $10 \%$ of the range. While the color legend extends from 0 to $0.853 \mathrm{~kW}$, the peak load in Fig. 1 is $8.53 \mathrm{~kW}$. The loads ranging from $0.853 \mathrm{~kW}$ to $8.53 \mathrm{~kW}$ are thus represented by the same dark red color. This rescaling is needed because, as is shown in Fig. 2 , the load peaks are very high and infrequent compared to the load at other times. Without this rescaling, the smaller but more frequent changes in the load would not be observable on this diagram. Fig. 2 shows the load curve of a winter day (18th Jan 2008) for the same household. For comparison, the typical system load of the UK is also displayed. Clearly, a single domestic load behaves very differently from the national aggregated load.

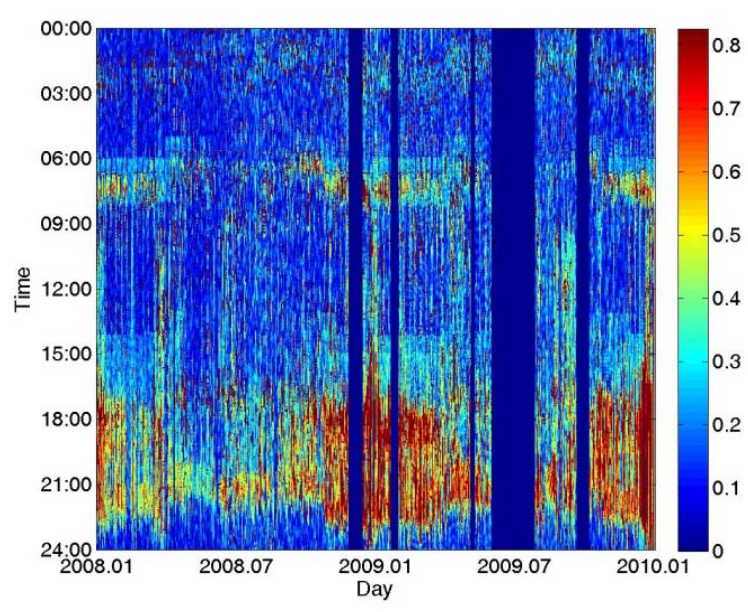

Fig. 1. Overall load pattern of one residential consumer.

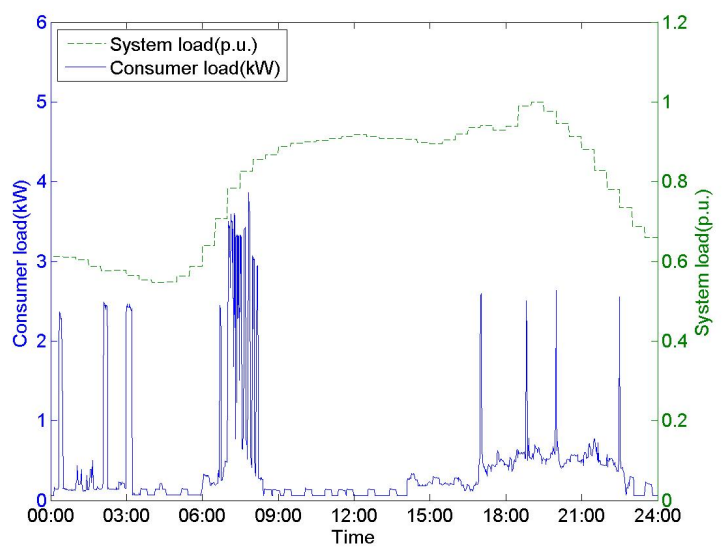

Fig. 2. Daily load curve of one residential consumer.

Although the daily load curve from Fig. 2 may not be the most representative one, it is evident that residential loads differ from the system pattern due to the presence of distinct sharp jumps, and have, typically, much lower load factors.

Since the type and rating of the appliances owned by each of the 12 households is known, the signature profiles of several types of high power appliances can be identified. Electric space heating, electric hobs, ovens, kettles, washing machines, tumble dryers and dishwashers are each characterized by peak demands of 1-3 kW. Electric showers can even reach up to $10 \mathrm{~kW}$ simply because they rely on high power resistances to provide fast performance. Most of the peaks these appliances create last from 1 to 15 minutes. The heating cycles of some washing machines and storage water heaters can reach 30 minutes.

The total after diversity maximum demand (ADMD) of all the consumers determines the capacity of the distribution transformers and conductors, i.e., the investment required in 


\section{Accepted Paper}

the LV network infrastructure. It is important to realize that the ADMD has relatively small relation with the peak demand of each consumer, but is strongly linked to how these peaks coincide.

It is possible to divide the load curve of each household into two parts: sharp jumps and basic load. The former represents the electricity usage of high power appliances and the latter corresponds to the rest of the domestic loads. Results reveal that the sharp jumps of each consumer have a much higher magnitude and a much lower load factor than the corresponding basic load. The most interesting finding is that the sharp jumps in the load of different consumers are nearly independent from each other. However, as expected, the correlation between the base loads of these consumers is relatively high. This means that the consumers included in this study rarely use high power appliance simultaneously. When this does happen, a control method could be applied to avoid coincident peaks. Such a control could significantly reduce the overall capacity needed by the LV feeder.

\section{CONTROL STRATEGY FOR DSM}

In this section we will postulate the implementation of a simple DSM control strategy to study the effect that it would have on domestic loads. The aim is to reduce the coincident peaks produced at the LV feeder level by high power appliances, without affecting the other loads. This is achieved by temporarily inhibiting the turn-on of by consumers of high power appliances that are not already in use. This control measure is activated when the total load on the LV feeder exceeds a preset value. The DSM controller then coordinates the temporary inhibition of certain high power appliances in each house. By shifting the sharp jumps caused by the various consumers, this DSM scheme thus reduces the number of coincident peaks.

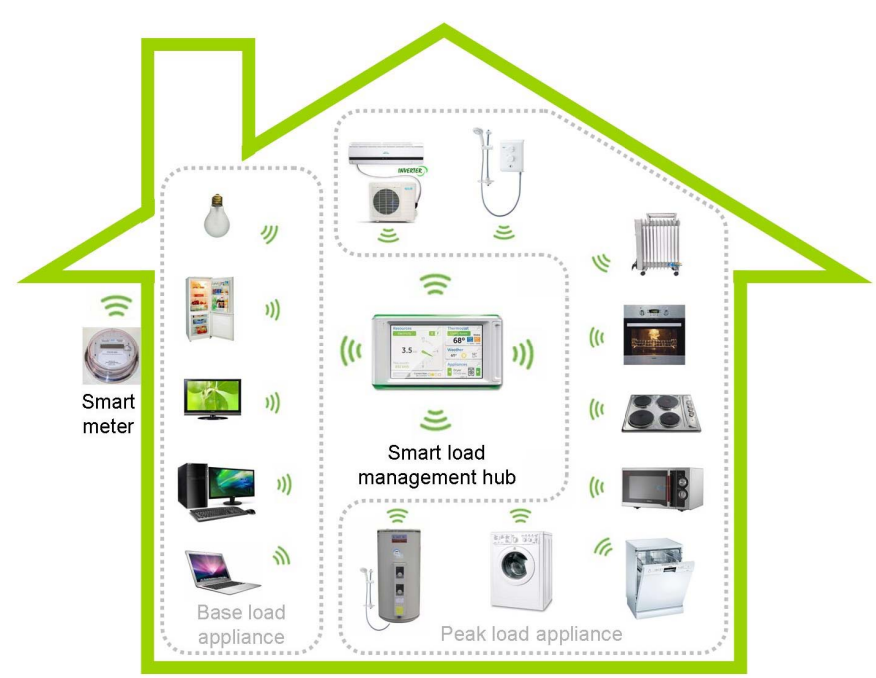

Fig. 3. Architecture for the proposed DSM scheme - at home.

The proposed DSM scheme could be deployed using a wireless system architecture similar to that shown in Fig. 3 and Fig. 4. Smart meters are able to remotely control (e.g., using ZigBee technology) the on and off inhibition of appliances. These smart meters are assumed to be capable of differentiating between high power demand appliances and those regarded as basic load. Smart meters are managed by the DSM centralized controller that monitors the local LV transformer.

The control strategy of the DSM controller is shown in Fig. 5. $K_{i}(i=1,2, \ldots, N)$ is the set of high power appliances with $N$ being the number of consumers, $P_{i t}$ is the power required by $K_{i}$ during minute $t, P_{t \Sigma}$ is the total load on the LV feeder, and $P_{r e f}$ is the preset control reference value. When the total load, $P_{t \Sigma}$ served by the transformer reaches $P_{r e f}$, the DSM controller inhibits those high power appliances that are not being used at that instant $\left(P_{i t}=0\right)$. This logic guarantees that the high power appliances which are already in-use are not 'disturbed'. The inhibited appliances $K_{i}$ become available when the total load of the feeder drops below the preset value.

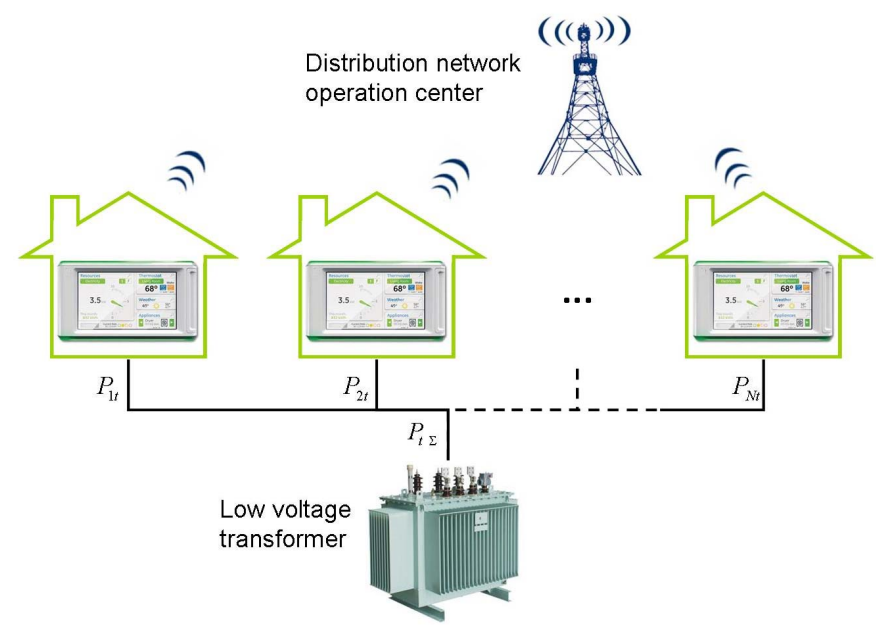

Fig. 4. Architecture for the proposed DSM scheme-LV feeder.

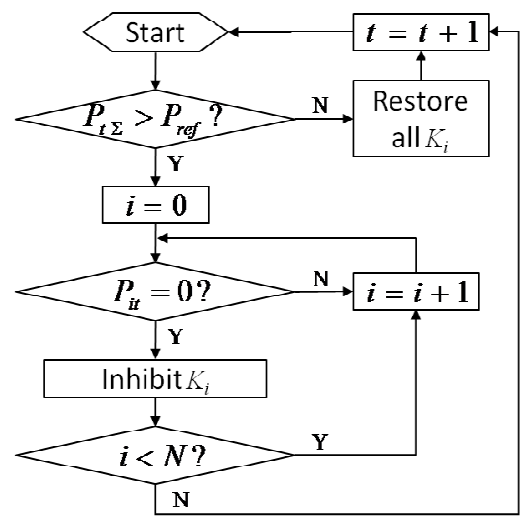

Fig. 5. Flow chart of DSM control strategy

The whole procedure can run very frequently, e.g. every 10 seconds and thus prevent the load spikes from happening simultaneously. To minimize the disturbance to the consumers, the proposed logic does not turn off appliances that are already in use, and only inhibits those that are turned off to avoid the total load to exceed the pre-set value. 


\section{Accepted Paper}

The proposed structure can be regarded as a generalized form of direct load control DSM . This structure can be used to control individual appliance when they are supplied by separate wires. It can also be expanded to cater for distributed generators with intermittent output (e.g. PV panels) connected to the LV network. The willingness of the consumer to accept this form of control and what compensation (if any) would be required need to be investigated. However, in this paper we first assume that this has been implemented and then discuss consumer acceptance based on the simulation results.

\section{RESULTS}

\section{A. Basic Data}

The proposed DSM scheme was tested using the domestic load data described in section II [12]. This data was first cleaned to take care of the missing records in each consumer's time series. Firstly, consumers with less than $90 \%$ load data were excluded. Secondly, among the remaining series, days that include one or more unavailable consumer records are omitted. Following this pretreatment, there remains synchronous load data for 12 consumers over 354 days. The maximum of aggregated load of these 12 consumers is 41.79 $\mathrm{kW}$.

To evaluate the coincidence of peak loads, we introduce the concept of simultaneity factor, which is calculated as follows:

$$
\eta=\max _{t \in[1, T]}\left[\sum_{i=1}^{12}\left(D_{i t}\right)\right] / \sum_{i=1}^{12} \max _{t \in[1, T]}\left(D_{i t}\right)
$$

where $D_{i t}$ is the load of consumer $i$ at $t$, and $T$ is the total number of minutes over the data available. The index indicates the extent to which the maximum loads of each individual consumer happen simultaneously. It has a maximum value of one, which is the case when the maximum load of each consumer happens together. This concept is used in this paper to evaluate the effect of decreasing the maximum load under DSM. According to the data used, the aggregated maximum aggregated load of all 12 consumers is $139.97 \mathrm{~kW}$. This makes the simultaneity factor of the original load profile 0.2986 p.u., which means that the load on the peak load period of these 12 consumers is about one third of the aggregated peak load (over all the periods available) of each consumer.

\section{B. Simulation Results}

The control reference is set before each simulation using the simultaneity factor. For instance, if the control reference is set to 0.2 p.u., the DSM is activated when the aggregated load reaches $139.97 \times 0.2=27.99 \mathrm{~kW}$. The effect of the proposed DSM with different control references (from 0.29 p.u. down to 0.10 p.u. in steps of 0.01 ) was simulated to evaluate its overall impact. For each value of the reference the control strategy is applied chronologically. When the total load exceeds the control reference, all high power appliances $K_{i}$ that are not being used are inhibited, which is recorded as an "inhibition occasion". If such $K_{i}$ was going be used while inhibited (according to the historical load curve acquired), the usage of the appliance is shifted. This represents a "waiting occasion".
The inhibited appliances are restored until the total load of all consumers drops within the limit of the the set of control reference. Fig. 6 gives an illustrative example of this shifting effect. The usage of one consumer's electric shower is shifted for 6 minutes to avoid coincident peaks. The control measure reduces the peak load by more than $8 \mathrm{~kW}$ (i.e. more than $20 \%$ of the original peak).
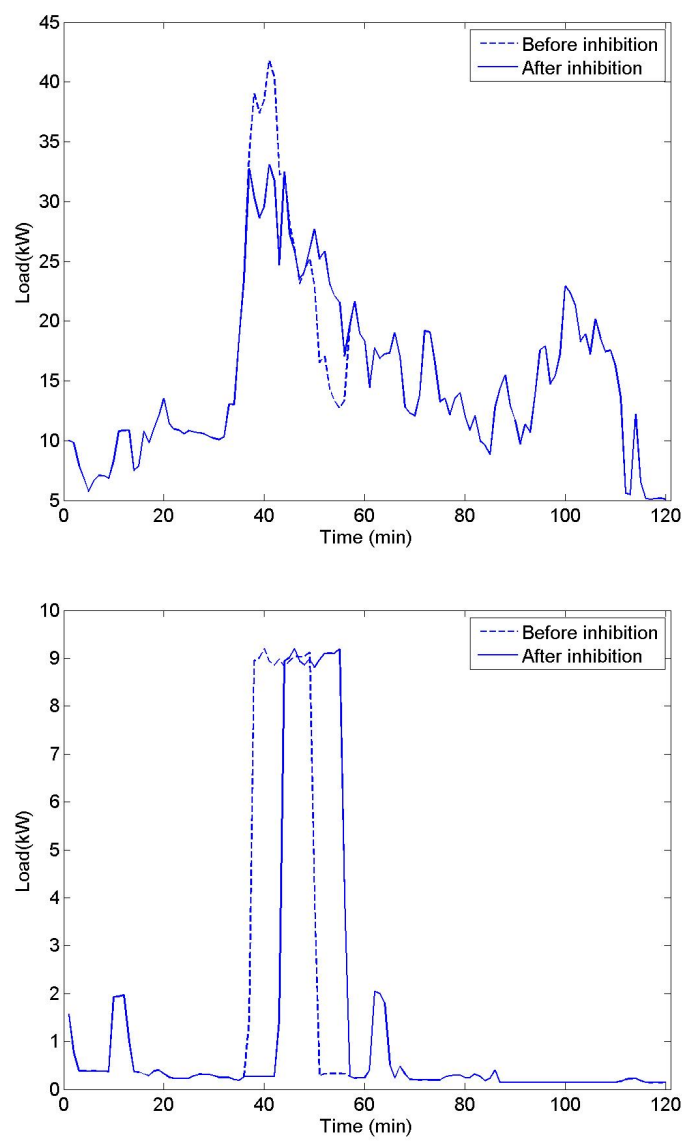

Fig. 6. Illustrative example of waiting occasion: the aggregated load curve (top) and the load curve of the consumer being controlled (bottom).

Table I summarizes the simulation results for different control references. This table gives the simultaneity factor after control ( $S F$ ), the peak load after control ( $P L$ ) and the relative decline of peak load $(\triangle P L)$ as a function of the control reference $(C F)$ ). Table II shows the average number of waiting occasions per consumer $(N W)$, average duration of each waiting occasion ( $D W$ ), average number of inhibition occasions per consumer $(N I)$ and average duration of each waiting occasion ( $D I)$, respectively. The results of Table II are plotted in Fig. 7 and Fig. 8.

TABLE I

DSM SiMUlation RESUltS WITH DIFFERENT CONTROL REFERENCES

\begin{tabular}{cccc}
\hline$C F$ (p.u) & $S F$ (p.u.) & $P L \mathbf{~ k W}$ & $\Delta P L$ \% \\
\hline 0.29 & 0.2986 & 41.79 & $0.00 \%$ \\
0.28 & 0.2986 & 41.79 & $0.00 \%$ \\
0.27 & 0.2986 & 41.79 & $0.00 \%$ \\
0.26 & 0.2986 & 41.79 & $0.00 \%$
\end{tabular}




\section{Accepted Paper}

\begin{tabular}{llll}
0.25 & 0.2986 & 41.79 & $0.00 \%$ \\
0.24 & 0.2986 & 41.79 & $0.00 \%$ \\
0.23 & 0.3004 & 42.05 & $-0.63 \%$ \\
0.22 & 0.3004 & 42.05 & $-0.63 \%$ \\
0.21 & 0.2991 & 41.86 & $-0.17 \%$ \\
0.20 & 0.2598 & 36.36 & $12.99 \%$ \\
0.19 & 0.2589 & 36.23 & $13.31 \%$ \\
0.18 & 0.2589 & 36.23 & $13.31 \%$ \\
0.17 & 0.2589 & 36.23 & $13.31 \%$ \\
0.16 & 0.2589 & 36.23 & $13.31 \%$ \\
0.15 & 0.2366 & 33.11 & $20.77 \%$ \\
0.14 & 0.2366 & 33.11 & $20.77 \%$ \\
0.13 & 0.2366 & 33.11 & $20.77 \%$ \\
0.12 & 0.2366 & 33.11 & $20.77 \%$ \\
0.11 & 0.2366 & 33.11 & $20.77 \%$ \\
0.10 & 0.2366 & 33.11 & $20.77 \%$ \\
\hline
\end{tabular}

TABLE I

STATISTICS OF WAITING OCCASIONS AND INHIBITION OCCASIONS WITH DIFFERENT CONTROL REFERENCES

\begin{tabular}{ccccc}
\hline$C F$ (p.u) & $N W$ (times) & $D W$ (min) & $N I$ (times) & $D I$ (min) \\
\hline 0.29 & 0.00 & 0.00 & 0.67 & 1.00 \\
0.28 & 0.00 & 0.00 & 0.67 & 2.00 \\
0.27 & 0.00 & 0.00 & 1.33 & 2.00 \\
0.26 & 0.00 & 0.00 & 1.33 & 3.13 \\
0.25 & 0.08 & 2.00 & 2.17 & 2.54 \\
0.24 & 0.08 & 3.00 & 2.17 & 2.92 \\
0.23 & 0.25 & 1.67 & 5.58 & 1.61 \\
0.22 & 0.25 & 1.67 & 6.08 & 1.90 \\
0.21 & 0.42 & 1.60 & 14.42 & 1.76 \\
0.20 & 0.75 & 2.33 & 24.50 & 1.88 \\
0.19 & 1.67 & 1.70 & 40.50 & 1.94 \\
0.18 & 3.58 & 1.88 & 64.25 & 2.12 \\
0.17 & 6.33 & 1.97 & 116.17 & 2.17 \\
0.16 & 10.92 & 2.10 & 195.75 & 2.28 \\
0.15 & 19.33 & 2.47 & 315.92 & 2.54 \\
0.14 & 28.50 & 2.61 & 473.17 & 2.75 \\
0.13 & 44.25 & 3.00 & 712.83 & 2.94 \\
0.12 & 71.75 & 3.16 & 1142.50 & 3.01 \\
0.11 & 118.92 & 3.56 & 1918.25 & 3.21 \\
0.10 & 199.17 & 4.10 & 2941.75 & 3.65 \\
\hline
\end{tabular}

From the results, it is clear that the proposed DSM effectively brings down the peak of the aggregated load. When the control reference is set at 0.19 p.u. the actual simultaneity factor drops to 0.2197 p.u., a $13.31 \%$ decrease in terms of peak load for the uncontrolled scenario. However, the decrease in the peak load with the control reference is not continuous because of the low probability of coincident peak demands (e.g. from 0.20 p.u. to 0.16 p.u.).

The statistics of the waiting times for the inhibited appliances and the number of inhibitions are also very interesting results. Firstly, the numbers of waiting occasions and inhibitions increase exponentially with tighter control references, while the average durations do not change significantly. Secondly, the number of waiting occasions is significantly smaller than that of inhibitions. This is because not all the inhibitions cause the end user to wait before turning on a high power appliance. In fact, the inhibitions the DSM commands would hardly disturb the consumer: when the control reference is set at 0.16 p.u. (which achieves a saving of $13.31 \%$ peak load), each consumer should expect to have to wait only of 1.66 occasions per year an average, with a mere 1.7 minutes average waiting time for each occasion.
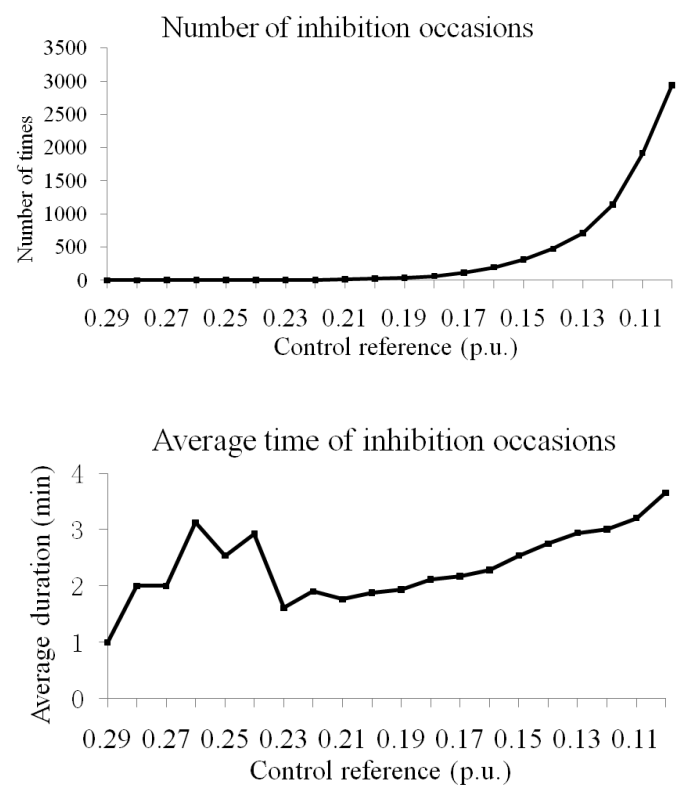

Fig. 7. Inhibition occasions: average number of times and average duration.
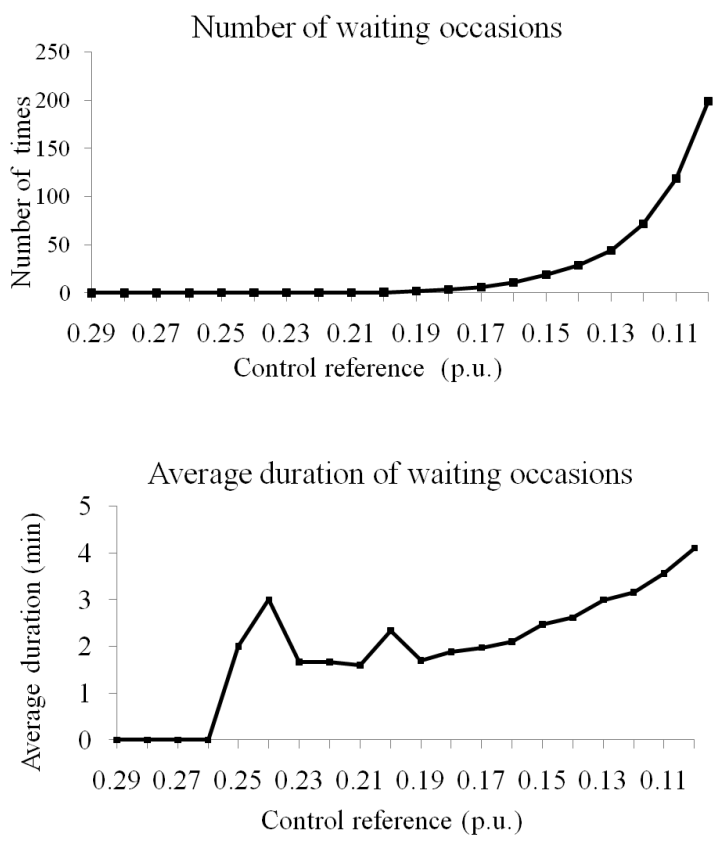

Fig. 8. Waiting occasions: average number of times and average duration.

\section{Discussion}

The simulation results reveal that the peak demand of a group of residential consumers can be reduced through changing their coincidence. The consumers are not disturbed too often or for too long and their peak demands are not significantly reduced. This means that the weak correlation of consumer peak demand has a lot of potential for DSM. These results could help in the design of the DSM strategies that strike a good balance between the utility's capacity savings and the consumers' inconvenience. More importantly, these results could provide a reference for setting the guaranteed maximum inhibition occasions in the DSM contract with 
consumers. Consumers will be happier to accept such DSM schemes if they are told that interruptions will occur only a few times per year and last only a few minutes. This could contribute to understanding of the role that public attitudes towards DSM technology have in shaping a flexible LV network.

The proposed control strategy could also be applied when electric vehicles (EV) represent a significant number of 'high power appliances'. Interrupting the charging of an electric vehicle for a few minutes is clearly not a major inconvenience. This makes the EV the ideal appliance for such a DSM scheme. Different priorities could be introduced in the control strategy and EV's could be the first loads to be inhibited when the load is close to the control reference. Since most electric vehicles might be charged during the peak time of residential load, avoiding charging using this control strategy could significantly reduce the peak load and would undoubtedly defer or reduce the need for network reinforcements.

Only 12 consumers were used in the simulations presented in this paper. It can be seen that there is more potential capacity savings when considering more consumers, since the coincident peak demands of more consumers happens more rarely. Thus, with the same level of disturbance, the savings in larger groups of consumers would potentially be higher than in a smaller group.

According to the electric usage information from the survey, none of these 12 consumers uses electric space heating (ESH). The results obtained in this paper thus only represent the nonESH situation. ESH can usually improve consumer's load factor. Taking ESH as a control object that can be inhibited during coincident peaks time would help the whole residential LV network achieve a higher efficiency. Furthermore, the control will cause less inconvenience since the thermal inertia of space heating is large compared with the short waiting duration.

\section{CONCLUSIONS}

This works introduces a Demand Side Management (DSM) strategy for reducing the coincident peak load in residential LV feeders. It provides insight on the impact of the proposed DSM scheme (or similar ones) on residential consumers. Simulations results demonstrate how beneficial this scheme could be to release capacity in LV feeders. More importantly, these results also show that the effect on consumers, i.e., on their ability to use their appliances, could be insignificant. This work could help improve the public acceptance of DSM, and also contribute to the design of DSM schemes in terms of technology and dynamic pricing.

\section{ACKNOWLEDGMENT}

The copyright of the data used for this paper is held by I. Richardson and M. Thomson from Loughborough University, Department of Electronic and Electrical Engineering, Centre for Renewable Energy Systems Technology. More details on this data can be found at:

www.esds.ac.uk/findingData/snDescription.asp?sn=6583.

\section{REFERENCES}

[1] D. G. Infield, J. Short, C. Home, and L. L. Freris, "Potential for Domestic Dynamic Demand-Side Management in the UK," IEEE Power Engineering Society General Meeting, 2007.

[2] M. Newborough, and P. Augood, "Demand-side management opportunities for the UK domestic sector," IEE Proc. Generation, Transmission and Distribution, vol. 146, no. 3, pp. 283-293, May. 1999.

[3] A. Molderink, V. Bakker, M. G. C. Bosman, J. L. Hurink, and G. J. M. Smit, "Management and Control of Domestic Smart Grid Technology," IEEE Trans. Smart Grid, vol. 1, no. 2, pp. 109-119, Sep. 2010.

[4] V. Hamidi,; F. Li; L. Yao; and M. Bazargan, "Domestic demand side management for increasing the value of wind," 2008 CICED China International Conference on Electricity Distribution, pp. 1-10.

[5] P. Ravibabu, A. Praveen, C. V. Chandra, P. R. Reddy, and M. Teja, "An approach of DSM techniques for domestic load management using fuzzy logic," IEEE International Conference on Fuzzy Systems, pp. 13031307, Aug. 2009.

[6] M. S. Majid, H. A. Rahman, M. Y. Hassan, and C. A. Ooi, "Demand side management using direct load control for residential," 4th Student Conference on Research and Development, pp.241-245, Jun. 2006.

[7] S. Koch, D. Meier, M. Zima, M. Wiederkehr, and G. Andersson, "An active coordination approach for thermal household appliances - local communication and calculation tasks in the household," 2009 IEEE Bucharest Power Tech Conference, June 28th - July 2nd, Bucharest, Romania, 2009.

[8] V. Hamidi, F. Li, and F. Robinson, "Demand response in the UK's domestic sector," Electric Power Systems Research, vol. 79, no. 12, pp 1722-1726, Dec. 2009.

[9] J. C. van Tonder, and I. E. Lane, "A load model to support demand management decisions on domestic storage water heater control strategy," IEEE Trans. on Power Systems, vol. 11, no. 4, pp. 1844-1849, Nov. 1996.

[10] C. Doyle, C.T. Gaunt, and R. Herman, "Using load research data to assess demand side management interventions," 40th International Universities Power Engineering Conference (UPEC), Cork, Ireland 2005.

[11] H. Sikai, and D. Infield, "The potential of domestic electric vehicles to contribute to Power System Operation through vehicle to grid technology," 44th International Universities Power Engineering Conference (UPEC), Glasgow, 2009.

[12] I. Richardson, M. Thomson, "One-Minute Resolution Domestic Electricity Use Data, 2008-2009" [Online]. Available: www.esds.ac.uk/findingData/snDescription.asp?sn=6583

\section{BIOGRAPHIES}
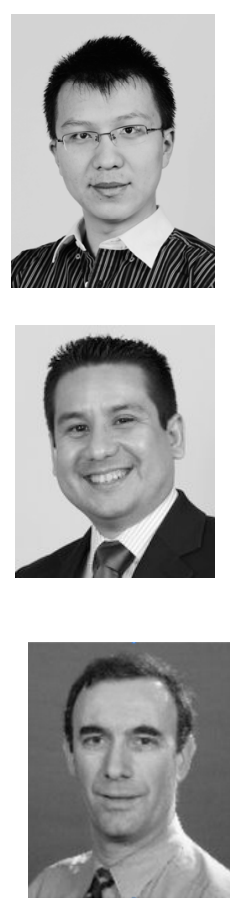

Ning Zhang (S'10) received his B.Sc. degree in Electrical Engineering Department in 2007 from Tsinghua University, Beijing, China. He is currently is a $\mathrm{Ph}$. D candidate in the electrical engineering field in the same university.

His research interests include power system planning with renewable energy, renewable energy statistic characteristic analysis and operation simulation, power system dispatching with renewable energy.

Luis F. Ochoa (S'01-M'07) received the B.Eng. degree from UNI, Lima, Peru, in 2000 and the M.Sc. and Ph.D. degrees from UNESP, Ilha Solteira, Brazil, in 2003 and 2006, respectively.

$\mathrm{He}$ is a Lecturer in Smart Distribution Networks at The University of Manchester, UK. His current research interests include network integration of distributed energy resources and distribution system analysis. Dr. Ochoa is a member of the IET.

Daniel S. Kirschen (M'86, SM'91, F'07) received the electrical and mechanical engineer's degrees from the Université Libre de Bruxelles, Belgium, in 1979 and the M.S. and Ph.D. degrees from the University of Wisconsin, Madison, in 1980 and 1985, respectively.

$\mathrm{He}$ is currently Close Professor in Electrical Engineering at the University of Washington. 